\title{
PRESSURE FOR TRUST-BASED EFFICIENCY SHAPED THE EVOLUTION OF LANGUAGE
}

\author{
Chris Knight \\ chris.knight@live.com \\ Department of Anthropology, University College London, \\ London, United Kingdom
}

\begin{abstract}
For human spoken language to emerge, selection pressures must have acted upon a primate-style precursor that had evolved subjet to the constraints of Darwinian signal evolution theory. Science is a search for conceptual unification. Consistently applied, a single new Darwinian pressure - selection for trust-based efficiency - suffices to explain the core features which distinguish speech from nonhuman primate vocal communication.
\end{abstract}

\section{Introduction}

This paper attempts to combine what we know about the evolution of communication in general with the emergence of language in particular, bringing into alignment two apparently irreconcilable theoretical paradigms Darwinian signal evolution theory on the one hand, historical linguistics including grammaticalization theory on the other.

\section{Why apes don't speak}

When communication is efficient, detailed information is conveyed accurately and at speed. From a human standpoint, the grunts, calls and screams of primates seem low in conceptual content and strikingly repetitive, as if messages had to overcome resistance from listeners on guard against being tricked. Resistance thwarts efficiency by forcing vocalisers to amplify and repeat. Fast and efficient communication presupposes minimal resistance from listeners who trust that communicative intentions are honest and trickery therefore unlikely.

It used to be thought that chimpanzee vocalizations were limited to involuntary grunts and screams expressing physical and emotional states (e.g. Goodall, 1986: 114-145). But recent studies in the wild have recorded food calls directed at specific individuals, indicating a cooperative intent (Schel et al., 2013a). Vocal alarms may also be volitional and intentional. In one experiment, 
two chimps were surprised by a model snake which had been deliberately placed along their path. The one who first noticed began 'hooing' while looking back and forth between his partner and the snake, stopping once confident that the other had seen the object (Schel et al., 2013b). Here, there are no grounds for listener mistrust or suspicion since the referent can be immediately checked out. It would be surprising if the vocalizer 'hooed' to its companion in a cooperative way about an imaginary snake. It would be still more astonishing if the listener heard the 'hoo', saw no snake - yet still played along with the patent fiction.

If great ape vocal communication can be intentional, where exactly is the language frontier which these animals seem unable to cross? Primatologists (e.g. Bergman et al., 2016; Seyfarth and Cheney, 2014, 2016; Vilain et al., 2011) often deny any Rubicon, viewing human capacities for vocal communication as modified extensions of those of our primate cousins or ancestors. In the opposite camp, most theoretical linguists (e.g. Bickerton, 1990; Berwick and Chomsky, 2016) point out that, for all their abilities, our ape relatives have not reached even the first rung of the ladder leading to syntactically complex speech.

\section{From a standpoint in signal evolution theory, language should not exist}

The faculty of language considered broadly (Hauser et al., 2002) is not one module but an assemblage of previously unrelated parts. The necessary auditory capacities, vocal organs and moveable components such as lips and tongue certainly evolved as adaptations to non-linguistic functions, becoming finetuned over evolutionary time to serve radically new ends. It might seem tempting to conceptualize the pressures responsible for this process of exaptation and convergence as 'selection pressures for speech'. But nothing in Darwinian theory permits us to envisage adaptation to achieve some future goal. Adaptation is always to the present, compelling us to envisage selection pressures prior to speech. Instead of assuming linguistic concepts from the outset, therefore, we need to envisage a fundamental pre-linguistic principle which, consistently applied, might have led in a direction toward speech. Since we cannot yet appeal to language, we have no choice but to rely on concepts appropriate within evolutionary biology.

Modern Darwinian signal evolution theory can be traced to the early work of Dawkins and Krebs (1978), who distinguish two opposite selection pressures which determine how signals evolve. One runs counter to efficiency in favouring loud, repetitive, extravagant displays; the other favours speed and efficiency. Normally, conflicts of interest prompt receivers to resist incoming signals, forcing producers to amplify and repeat in order to get through. Although primates in some contexts may engage in so-called 'cheap talk' (Silk 
et al., 1999), pressure for reliability means that they never get close to the fast, cheap, super-efficient extreme represented by human speech.

The costs to an animal of producing a signal may be divided into two parts the 'efficacy cost' or investment needed to ensure clear transmission, and the 'strategic cost' needed to demonstrate signal reliability (Maynard Smith and Harper, 2003). To arrive at the fast and efficient extreme represented by speech, the second component needed to be reduced to zero, freeing speakers from all except efficacy costs. This could only happen where listeners were sufficiently trusting, requiring no demonstration of signal reliability at all.

Bonobos, chimpanzees and many other primates seem to have capacities for symbolic communication which they don't use in the wild (Fouts 1997; SavageRumbaugh 1998). Early hominins must surely have possessed at least equal capacities, yet we find no compelling archaeological evidence for art or symbolic usage until strikingly late, around the time when modern Homo sapiens begins to emerge (Henshilwood et al., 2002, 2009; Henshilwood and Dubreuil, 2009; Watts, 1999, 2009, 2014; Watts et al., 2016). This returns us to our opening discussion. There must have been some powerful factor blocking the emergence of either words or grammar throughout the greater part of hominin evolution.

Grammaticalization theory (Meillet, 1903; Heine et al., 1991; Deutscher 2005) has clarified how grammatical structures emerge and systematically change over historical time. Yet despite progress in applying such insights to evolutionary questions (Heine and Kuteva, 2007, 2012; Hurford, 2012) it remains unclear what social, cognitive or neural developments initially enabled grammaticalization to get under way, or what prevented it from happening previously.

Signal evolution theory reminds us of the role which must initially have been played by trust in enabling the first faltering steps toward words and grammar. Without trust in communicative intentions, not even those first steps could have been taken. Where listeners are suspicious from the outset, each successive signal must inspire confidence by demonstrating in some way that it is reliable (Zahavi and Zahavi, 1997), a requirement which slows things down, prompts repetition and impedes efficiency. Repetitive ape hoots, screams and other costly signals are just not the kind of elements that can be reduced, combined, or recursively structured in the manner that grammaticalization requires.

\section{Design features of speech}

Since the work of Hockett (1960), linguists have catalogued an impressive list of features to distinguish speech from animal systems of communication. Spoken 
language is (1) symbolic, (2) metaphorical in principle, (3) grammatically complex, (4) capable of displaced reference and (5) digital in format. Instead of seeking to explain each feature by a separate theory, it would be better if we could explain them all on the basis of a single parsimonious theory.

4.1 Symbolism. Although wild-living apes do not use symbols, this is not because they lack the capacity. Classic studies of captive apes have shown that these intelligent animals have no difficulty in learning and using arbitrary symbols (Fouts, 1997; Savage-Rumbaugh et al., 1998). So why don't they use them in the wild? To explain this, we need to investigate social relations - in particular, primate expectations of honesty and trust.

The philosopher Eco (1976: 7) famously defined a symbol as anything that 'can be used in order to lie'. Yet from a standpoint in primate communication, the problem is that words are already 'lies', regardless of their subsequent use. To a wild-living chimpanzee, every vocalization of the kind made in speech would be perceived as a potentially deceptive fake. This is theoretically challenging because, although primate deception can work, it has to be sufficiently rare for victims to be tricked into expecting honesty. A situation in which deceptions had become normal would be hard to explain.

Symbols are often defined as arbitrary social conventions (Peirce, 1940). But this fails to capture the element of falsehood involved. Sperber's definition is more helpful here. "“That's symbolic” Why? Because it is false' (Sperber, 1975: 4). A symbol is a falsehood given currency by social convention. The necessary social element, a new kind of trust, has been linked by some scholars to the transition from primate-style dominance politics to the egalitarianism of extant hunter-gatherers (Erdal and Whiten, 1994, 1996; Whiten and Erdal, 2012; Whiten, 1999; Lewis, 2009, 2014).

Before the evolution of language could begin, if these insights are correct, individuals had to start accepting patent falsehoods on trust (Knight, 2008, 2009, 2014; Knight and Lewis, 2014, 2017). We might imagine a hominin 'hooing' to its companion when no snake was visible. If instead of dismissing the false alarm, the listener showed a cooperative interest in imaginary snakes, the way would be open for the multiple complexities of symbolic language to evolve.

4.2 Metaphor. The creative use of language depends crucially on the ability to deploy metaphor (Deutscher, 2005; Smith and Hoefler, 2014). Beyond this, metaphor is central to the way humans think (Lakoff and Johnson, 1987). 'Conceptualising one thing while meaning another' is one way to formulate the underlying principle, but metaphorical usage boils down to falsehood: 'Generally it is only when a sentence is taken to be false that we accept it as a 
metaphor and start to hunt out the hidden implication' (Davidson, 1979: 40). This hidden implication is a chosen aspect of reality which for joint purposes we feel able to take as truth. When a metaphor becomes common currency, we forget its original incongruity, which was the quality necessary to provoke thought. In becoming conventionally accepted, previously striking metaphors (such as 'bottle neck') become interpreted literally - that is, as settled features of the linguistic code ('bottleneck'). The cyclical logic through which metaphors arise, fade, die and are replaced by novel metaphors accounts quite generally for the creativity of language and its restless unfolding over historical time (Deutscher, 2005).

We might suppose that metaphor requires no special interpretive abilities, just a willingness to accept patent falsehood on trust. But we must not underestimate the cognitive challenges here. For metaphor to work, speakers and listeners must put themselves in each other's shoes, attempting to guess at one another's communicative intentions using contextual cues, memory and imagination (Grice, 1969; Sperber and Wilson, 1986). The collaboration required for the development of such 'intersubjectivity' (Tomasello and Rakoczy, 2003) or 'deep social mind' (Whiten, 1999) is clearly a social and political factor, and it is this which most decisively sets humans in a world apart from apes.

4.3 Grammar. Evolutionary theorists once assumed the need for two separate theories, one to explain the emergence of words in isolation and another to explain how grammar evolved at a later stage (e.g. Bickerton, 1990). The requirement for two stages seemed unavoidable in the days when the dominant theoretical paradigm placed words in a quite separate category from grammatical rules (e.g. Pinker, 1999). Nowadays, most evolutionary linguists embrace some version of construction grammar, which treats words and rules alike as constructions acquired by children simultaneously and in essentially the same way (Tomasello, 2006; Goldberg, 2006). So two separate evolutionary stages are no longer required. Once humans were using metaphor in the broadest sense - once they could say one thing while meaning another (Sperber and Wilson, 1987) - words and rules would simultaneously have emerged (Smith and Hoefler, 2014).

4.4 Displaced reference. The ability to refer to events or objects outside the here and now is often conceptualized as a useful additional feature of language. But I prefer to invoke Austin (1978) and Searle (1969), who make the more profound point that any speech act is a move internal to a shared virtual (socially constructed). If that is accepted, all linguistic reference is of necessity displaced. 
Even to point at something is to take action in the world as jointly construed, so displacement is involved here, too.

There is no need for a separate theory to explain this. Monkeys and apes inhabit reality, not virtual reality, and so their signalling naturally reflects this. Every primate gesture or vocalization is designed to alter reality as perceived from the standpoint of the signaller. But to inhabit a socially constructed landscape of 'institutional facts' (Searle, 1996) is to be happy with shared fictions, trusting that they are not exploitative tricks. So whatever it was that enabled hominins to accept one another's fictions would simultaneously have enabled displaced reference.

4.5 Digital format. A digital switch is an all-or-nothing choice. Saussure (1983 [1915]) famously observed that in language, there are no positive terms, only categorical differences between them. Jakobson took this insight a step further with his celebrated theory of distinctive features, arguing that the speech sounds of the world's languages reduce to a limited set of binary oppositions, each switching between one phoneme and another and, potentially, between one selected meaning and another (Jakobson et al., 1951). It is worth mentioning that although the vocalizations of some species (e.g. songbirds and cetaceans) display digital structure on the level of sound, digital format does not extend to semantics as well. If a whale or songbird were to replace one note in a sequence by another, this would not systematically modify the meaning of the entire song. With spoken language, by contrast, replacing a voiced $<$ b $>$ by an unvoiced $<$ p $>$ in a sentence might well transform the meaning of the entire utterance.

An ape, on hearing a vocalization, homes in on the multiple acoustic gradations of each incoming sound as it arrives. By contrast, as a guide to meaning, the human speaker-listener just wants to know whether this or that distinct vowel or consonant is intended. A useful way to conceptualize the issues at stake is to contrast speaking with singing. When we sing, our audience will naturally expect the whole performance, listening to the melody for as long as it takes. Resorting to shorthands just won't do. Abbreviation is unthinkable because our focus of interest is not the singer's intentions but their actual performance - the impact of the melody and the precise acoustic quality of those sounds. No performance will satisfy an audience if, on grounds of speed and efficiency, the singer were to compress the output into a sequence of rapid-fire digits.

Although music combines categorically distinct notes and is in that sense a discrete-combinatorial system, where meanings are concerned we remain in a graded, analog realm. Song may have language-like aspects and speech may be melodic (see chapters in Bannan, Ed., 2012; Wallin et al., 2000), yet it is 
pressure to transmit conceptual information at speed which drives speech to diverge so radically from music and song. As the extreme limit of efficiency is approached, shorthand abbreviations become reduced to zero-cost digital contrasts.

A digital computer is one which moves by sudden jumps or clicks from one quite definite state to another. Turing (1950) clarifies that, strictly speaking, there are no such machines. Everything in real life moves continuously. Even with electric lighting, explains Turing, 'it is a convenient fiction that each switch must be definitely on or definitely off. There must be intermediate positions, but for most purposes we can forget about them'. The fact that digits appear only when we forget about intermediate states - ignoring irrelevant gradations in sensory experience - tells us that they are not physically real distinctions but hallucinations or abstractions.

Apes are not willing to ignore subtle gradations. The key fact for any evolutionary account is that a nonhuman primate, on hearing conspecifics' graded calls, will not interpret them as abstract digits. Far from ignoring intermediate states, the animal will home in on those subtle gradations which alone can provide information about the quality and reliability of what it hears. Turing's insights help us to appreciate that digital format becomes possible only when listeners feel able to overlook irrelevant performance gradations, vesting their trust, yet again, solely in communicative intentions.

\section{Conclusion}

Before fictions became acceptable currency, the design features of language reviewed here were barred by the constraints inherent in Darwinian signal evolution theory. Where each signal must demonstrate a strategic cost, not one of language's special features can evolve. From a standpoint in the evolution of animal communication, language therefore seems to be theoretically impossible (Knight, 2016). If, despite this, it did evolve, it is not because Darwinian theory is wrong. Rather, it is that virtual action involves no material costs, falling beyond the remit of this whole body of theory. For reasons that I have not explored here (see Knight, 2008, Knight and Lewis, 2014), humans in speech communities vested in one another something approaching infinite trust. This was not because they were unconditionally honest, but simply because all communication was now internal to a shared virtual world.

There is an intimate connection between the intensity of cooperation across a network and levels of honesty and trust. Darwinian theorists (e.g. Nowak, 2006) have developed sophisticated abstract models to explain how cooperation between natural organisms evolves, setting aside complexities such as gender 
and politics for the sake of simplicity. When dealing with the evolution of human hunter-gatherer egalitarianism, however, such complexities cannot be ignored. It is beyond the scope of this paper to detail how interpersonal trust would have been raised by limiting within-group sexual competition and conflict, or how evolving human females enhanced their fitness by cementing childcare alliances in ways which also strengthened gender egalitarianism (Knight and Lewis, 2014, 2017). An ambitious intellectual school (Hrdy, 2009; Burkart et al., 2009; Power and Watts, 1996; Power, 2009; Opie and Power, 2009) has recently been applying basic Darwinian theory to the specific case of hominin females with large-brained babies needing to trust one another and cooperate closely in order to nurture their unusually demanding offspring and also to secure provisioning support from males. Here, my aim has been limited to showing how the constraints obstructing language's emergence would have been lifted given sufficient trust. Once there was no need to demonstrate reliability, novel pressures for speed and efficiency would have come into play, leading to the unprecedented design features of speech.

Tolerance of patent falsehood takes listener trust well beyond anything which chimpanzees are prepared to extend to one another. Wild-living chimps have been shown to accept volitional, intentional vocal alarms where their veracity can be simultaneously confirmed. If only they were to take one step beyond that - to the point of welcoming false alarms - they would be crossing the Rubicon into a virtual world.

Science is a search for conceptual unification. The revolutionary new signal evaluation criterion permitting language to emerge was simply this: signals were deemed acceptable even when known to be false. This single step, taken habitually by socially intelligent modern humans, enabled the extraordinary complexities of language to pour out in a cascade.

\section{References}

Austin, J. L. (1978 [1955]). How to do things with words. Oxford: Oxford University Press.

Bannan, N. (Ed.), 2012. Music, language, and human evolution. Oxford: Oxford University Press.

Bergman, T. J., Beehner, J. C., Cheney, D. L., \& Seyfarth, R. M. (2003). Hierarchical classification by rank and kinship in baboons. Science, 302, 1234-1236.

Berwick, R. C. \& Chomsky, N. (2016), Why only us? Cambridge, MA: MIT Press.

Bickerton, D. (1990). Language and species. Chicago: University of Chicago Press. 
Davidson, R. D. (1979). What metaphors mean. In S. Sacks (Ed.), On metaphor (pp. 29-45). Chicago: University of Chicago Press.

Dawkins, R. \& Krebs, J. R. (1978). Animal signals: Information or manipulation? In J. R. Krebs \& N. B. Davies (Eds.), Behavioural ecology. An evolutionary approach (pp. 262-309). Oxford: Blackwell Scientific Publications.

Deutscher, G. (2005). The unfolding of language: The evolution of mankind's greatest invention. London: Random House.

Eco, U. (1976). A theory of semiotics. Bloomington, IN: Indiana University Press.

Erdal, D. \& Whiten, A. (1994). On human egalitarianism: An evolutionary product of Machiavellian status escalation? Current Anthropology 35(2): 175-183.

Erdal, D. \& Whiten, A. (1996). Egalitarianism and Machiavellian intelligence in human evolution. In P. Mellars \& K. Gibson (Eds.), Modelling the Early Human Mind (pp. 139-150). Cambridge: McDonald Institute Monographs.

Fouts, R. S. (1997). Next of kin: My conversations with chimpanzees. Harper Collins, New York.

Goldberg, A. E. (2006). Constructions at work: The nature of generalization in language. Oxford: Oxford University Press.

Goodall, J. (1986). The chimpanzees of Gombe. Patterns of behavior. Cambridge, MA and London: Belknap Press of Harvard University Press.

Grice, H. P. (1969). Utterer's meanings and intentions. Philosophical Review 78, 147-77.

Hauser, M. D. Chomsky, A. N. \& Fitch, W. T. (2002). The faculty of language: what is it, who has it, and how did it evolve? Science, 298, 1569-1579.

Heine, B., Claudi, U. and Hünnemeyer. F. (1991). Grammaticalization. A conceptual framework. Chicago and London: University of Chicago Press.

Henshilwood, C. S., d'Errico, F., Yates, R., Jacobs, Z., Tribolo, C., Duller, G. A. T., Mercier, N., Sealy, J. C., Valladas, H., Watts, I. \& Wintle, A. G. (2002). Emergence of modern human behavior: Middle Stone Age engravings from South Africa. Science 295: 1278-1280.

Henshilwood, C. S. \& Dubreuil, B. (2009). Reading the artifacts: gleaning language skills from the Middle Stone Age in southern Africa. In R. Botha \& C. Knight (Eds.), The Cradle of Language (pp. 41-61). Oxford: Oxford University Press.

Henshilwood, C., d'Errico, F., \& Watts, I., (2009). Engraved ochres from the Middle Stone Age levels at Blombos Cave, South Africa. Journal of Human Evolution 57(1): 27-47.

Hockett, C. (1960). The origin of speech. Scientific American 203(3), 88-96.

Hrdy, S. B. (2009). Mothers and others. The evolutionary origins of mutual understanding. London \& Cambridge, MA: Belknap Press of Harvard University Press.

Hurford, J. (2012). The origins of grammar. Oxford: Oxford University Press. 
Jakobson, R., C. Gunnar, M. Fant \& M. Halle, (1951). Preliminaries to speech analysis: The distinctive features and their correlates. Cambridge, MA: MIT Press.

Knight, C. (2008). 'Honest fakes' and language origins. Journal of Consciousness Studies, 15 (10-11), 236-48.

Knight, C. (2009). Language, ochre, and the rule of law. In R. Botha \& C. Knight (Eds), The cradle of language (pp. 281-303). Oxford: Oxford University Press.

Knight, C. (2016). Puzzles and mysteries in the origins of language. Language and Communication, vol. 50, pp. 12-21.

Knight, C. \& Lewis, J. (2014). Vocal deception, laughter, and the linguistic significance of reverse dominance. In D. Dor, C. Knight \& J. Lewis (Eds.), The social origins of language (pp. 297-314). Oxford: Oxford University Press.

Knight, C. \& Lewis, J. (2017). Wild voices: Mimicry, reversal, metaphor, and the emergence of language. Current Anthropology, 58(4): 435-453.

Lakoff, G. \& Johnson, M. (1980). Metaphors we live by. Chicago: University of Chicago Press.

Lewis, J. (2009). As well as words: Congo Pygmy hunting, mimicry, and play. In R. Botha \& C. Knight (Eds.), The Cradle of Language (pp. 236-256). Oxford: Oxford University Press.

Lewis, J. (2014). BaYaka Pygmy multi-modal and mimetic communication traditions. In D. Dor, C. Knight \& J. Lewis (Eds.), The Social Origins of Language (pp. 77-91). Oxford: Oxford University Press.

Maynard Smith, J. \& Harper, D. (2003). Animal Signals. Oxford: Oxford University Press.

Nowak, M. (2006). Five rules for the evolution of cooperation. Science, 314 (5805): 1560-1563.

Opie, K. \& Power, C. (2009). Grandmothering and female coalitions. A basis for matrilineal priority? In N. J. Allen, H. Callan, R. Dunbar \& W. James (Eds.), Early human kinship (pp. 168-186). Oxford: Blackwell.

Peirce, C. S. (1940). Logic as semiotic: the theory of signs. In J. Buchler (Ed.), The philosophical writings of Peirce (pp. 98-119). New York: Dover.

Pinker, S. (1999). Words and Rules. The ingredients of language. London: Weidenfeld and Nicolson.

Power, C. (2009). Sexual selection models for the emergence of symbolic communication: Why they should be reversed. In R. Botha \& C. Knight (Eds.), The cradle of language (pp. 257-280). Oxford: Oxford University Press.

Power, C., \& Watts, I. (1999). First gender, wrong sex, in H. L. Moore, T. Sanders, \& B. Kaare (Eds.), Those who play with fire: Gender, fertility and transformation in East and Southern Africa (pp. 101-132). London \& New Brunswick, N. J.: Athlone Press. 
Saussure, F. de (1983 [1915]). Course in general linguistics. Trans. R. Harris. London: Duckworth.

Savage-Rumbaugh, E. S. \& McDonald, K. (1988). Deception and social Manipulation in Symbol-using Apes. In R. W. Byrne \& A. Whiten (Eds.), Machiavellian intelligence (pp. 224-237). Oxford: Clarendon Press,

Schel, A. M., Machanda, Z., Townsend, S. W., Zuberbühler, K. \& Slocombe, K E. (2013a). Chimpanzee food calls are directed at specific individuals. In Animal Behaviour, 86(5), 955-965.

Schel, A. M., Machanda, Z., Townsend, S. W., Zuberbühler, K. \& Slocombe, K.E. (2013b). Chimpanzee alarm call production meets key criteria for intentionality. PLOS ONE 8(10), 1-11

Searle, J. R. (1969). Speech acts. An essay in the philosophy of language. Cambridge: Cambridge University Press.

Searle, J. R. (1996). The construction of social reality. London: Penguin.

Silk, J. B., Kaldor, E. \& Boyd, R. (1999). Cheap talk when interests conflict. Animal Behaviour 59: 423-432.

Smith, A. D. M. \& Hoefler S. H., (2016). From metaphor to symbols and grammar: the cumulative cultural evolution of language. In C. Power, M. Finnegan \& H. Callan (Eds.), Human origins: Contributions from social anthropology (pp. 153-179). New York: Berghahn.

Searle, J. R. (1969). Speech acts: An essay in the philosophy of language. Cambridge: Cambridge University Press.

Sperber, D. (1975). Rethinking symbolism. Cambridge: Cambridge University Press.

Sperber, D., \& Wilson, D. (1987). Relevance: Communication and cognition. Oxford: Blackwell.

Seyfarth, R. M., \& Cheney, D. L. (2014). The evolution of language from social cognition. Current Opinion in Neurobiology, 28, 5-9.

Seyfarth, R. M., \& Cheney, D. L. (2016). Precursors to language: Social cognition and pragmatic inference in primates. Psychonomic Bulletin \& Review, 24(1), 79-84.

Tomasello, M. (2006). Acquiring linguistic constructions. In D. Kuhn \& Siegler, R. (Eds.), Handbook of child psychology (pp. 255-98). New York: Wiley.

Tomasello, M., \& Rakoczy, H. (2003). What makes human cognition unique? Mind and Language 18:121-147.

Turing, A. M. (1950). Computing machinery and intelligence. Mind, 59, 433460.

Vilain, A., Schwarts, J.-L. Abry, C. \& Vauclair, J. (Eds.), (2011). Primate communication and human language. Vocalization, gestures, imitation and deixis in humans and non-humans. Amsterdam: John Benjamin.

Wallin, N. L., Merker, B. \& S. Brown (Eds.), The Origins of Music. Cambridge, MA: MIT Press. 
Watts, I. (1999). The origin of symbolic culture. In R. Dunbar, C. Knight \& C. Power (eds), The Evolution of Culture (pp. 113-46). Edinburgh: Edinburgh University Press.

Watts, I. (2009). Red ochre, body painting, and language: Interpreting the Blombos ochre. In R. Botha and C. Knight (Eds.), The cradle of language (pp. 62-92). Oxford: Oxford University Press.

Watts, I. (2014). The red thread: pigment use and the evolution of collective ritual. In D. Dor, C. Knight and J. Lewis (Eds), The social origins of language (pp. 208-227). Oxford: Oxford University Press.

Watts, I., Chazan, M. \& Wilkins, J. (2016). Early evidence for brilliant ritualized display: Specularite use in the Northern Cape (South Africa) between $\sim 500$ and $\sim 300 \mathrm{Ka}$. Current Anthropology, 57(3).

Whiten, A. (1999). The evolution of deep social mind in humans. In M. Corballis \& S. E. G. Lea (Eds,). The descent of mind: psychological perspectives on hominid evolution (pp. 173-193). Oxford: Oxford University Press.

Whiten, A., \& Erdal, D.. (2012). The human socio-cognitive niche and its evolutionary origins. Philosophical Transactions of the Royal Society B: Biological Sciences 367: 2119-2129.

Zahavi, A. and A. Zahavi (1997). The handicap principle. A missing piece in Darwin's puzzle. New York \& Oxford: Oxford University Press. 